\title{
The magnitude and characteristics of the population of cancer survivors: using population- based estimates of cancer prevalence to inform service planning for survivorship care
}

Linda Sharp ${ }^{1 *}$, Sandra Deady ${ }^{1}$, Pamela Gallagher ${ }^{2}$, Michal Molcho $^{3}$, Alison Pearce ${ }^{1}$, Audrey Alforque Thomas ${ }^{3}$, Aileen Timmons ${ }^{1}$ and Harry Comber ${ }^{1}$

\begin{abstract}
Background: Rising cancer incidence and survival mean that the number of cancer survivors is growing. Accumulating evidence suggests many survivors have long-term medical and supportive care needs, and that these needs vary by survivors' socio-demographic and clinical characteristics. To illustrate how cancer registry data may be useful in survivorship care service planning, we generated population-based estimates of cancer prevalence in Ireland and described socio-demographic and clinical characteristics of the survivor population.

Methods: Details of people diagnosed with invasive cancer (ICD10 C00-C96) during 1994-2011, and who were still alive on 31/12/2011, were abstracted from the National Cancer Registry, and tabulated by cancer site, sex, current age, marital status, initial treatment, and time since diagnosis. Associations were investigated using chi-square tests.

Results: After excluding non-melanoma skin cancers, 17-year cancer prevalence in Ireland was 112,610 (females: $58,054$ (52\%) males: $54,556(48 \%))$. The four most prevalent cancers among females were breast $(26,066)$, colorectum $(6,598)$, melanoma $(4,593)$ and uterus $(3,505)$ and among males were prostate $(23,966)$, colorectum $(8,207)$, lymphoma $(3,236)$ and melanoma $(2,774)$. At the end of $2011,39 \%$ of female survivors were aged $<60$ and $35 \%$ were $\geq 70$ compared to $25 \%$ and $46 \%$ of males $(p<0.001)$. More than half of survivors of bladder, colorectal and prostate cancer were $\geq 70$. Cancers with the highest percentages of younger $(<40)$ survivors were: testis $(50 \%)$; leukaemia (females: 28\%; males: 22\%); cervix (20\%); and lymphoma (females: 19\%; males: 20\%). Fewer female (57\%) than male (64\%) survivors were married but the percentage single was similar (17-18\%). More female (25\%) than male survivors (18\%; $p<0.001)$ were $\geq 10$ years from diagnosis. Overall, $69 \%$ of survivors had undergone cancer-directed surgery, and 39\%, 32\% and 18\% had received radiotherapy, chemotherapy and hormone therapy, respectively. These frequencies were higher among females than males (surgery: 82\%, 54\%; radiotherapy: 42\%, 35\%; chemotherapy: 40\%, 22\%; hormone therapy: 23\%, 13\%).

Conclusions: These results reveal the socio-demographic and clinical heterogeneity of the survivor population, and highlight groups which may have specific medical and supportive care needs. These types of population-based estimates may help decision-makers, planners and service providers to develop follow-up and after-care services to effectively meet survivors' needs.
\end{abstract}

Keywords: Cancer, Prevalence, Survivors, Supportive care, Unmet needs

\footnotetext{
* Correspondence: linda.sharp@ncri.ie

${ }^{1}$ National Cancer Registry, Building 6800, Cork Airport Business Park, Kinsale

Road, Cork, Ireland

Full list of author information is available at the end of the article
} 


\section{Background}

In most countries the number of people diagnosed with cancer is rising steadily. In Europe, an estimated 3.2 million cancers were diagnosed in 2006; by 2012, this had risen to 3.5 million [1,2]. This is a result of both demographic changes (i.e. population ageing) and changes in underlying risk. At the same time, survival for many cancers is improving - by $1-2 \%$ per annum - and 5 -year relative survival for all cancers combined now exceeds $50 \%[3,4]$. These trends mean that there are increasing numbers of "cancer survivors" (i.e. people living with and beyond a diagnosis of cancer [5]) in the population.

In the past, the life trajectory for most people diagnosed with cancer was one of inexorable decline. Nowadays, therapeutic advances, and a greater focus on addressing the side-effects and toxicities of treatment, mean that many people successfully complete primary treatment, recover substantial functional capacity, and can - potentially resume everyday activities [6]. However, this cannot be taken to suggest that survivors simply return to "normal life"; instead they must find a "new normal" that recognizes and accommodates cancer and its consequences [7-9]. For example, many survivors have complex health conditions which co-exist with their cancer [10], or arise as a consequence of treatment (see, for example, [11-16]). They also have an elevated risk of developing a second cancer [16]. In addition, evidence is accumulating that many survivors experience: significant functional and psychological problems and limitations; social, sexual and relationship difficulties; and financial/economic problems due to cancer and its treatment [17]. Taken together these issues mean that survivors may have considerable ongoing needs for medical and non-medical support and care long after their initial diagnosis and treatment. The prevalence, nature and extent of these supportive care needs vary by survivors' socio-demographic and clinical characteristics (see, for example, [18-23]). In addition, research from several healthcare systems suggests these needs often go unmet [21].

The resource requirements for supporting cancer survivors are likely to be quite different to those necessary for treating newly diagnosed cancers [24]. Therefore, estimates of the number of people living with cancer in the population - and a description of their characteristics could aid decision-makers, planners and service providers (both statutory and voluntary, in health and social care) in developing services, supports and other initiatives to meet survivors' needs.

Population-based cancer registries, which record and follow-up every cancer diagnosed within a defined population, operate in many countries worldwide; in the Europe Union, 26 countries have either regional or national registries [25]. Such registries are considered an essential component of any comprehensive cancer control programme. They provide robust data on cancer incidence, survival, and mortality in the population, and the only truly valid data for: monitoring and projecting the population-level burden of cancer (to inform service planning); assessing variations in incidence (to reveal possible differences in exposure to risk factors and provide information on effectiveness of prevention strategies); and examining patterns and trends in clinical outcomes (to evaluate quality of, and equity of access to, services) $[26,27]$. To date, however, registry data has not been extensively used to inform resource requirements for follow-up and after-care services. In order to illustrate how cancer registry data may be useful in survivorship care service planning, we aimed to: (i) generate population-based estimates of cancer prevalence in Ireland; and (ii) describe the socio-demographic and clinical characteristics of the population of people living with cancer. Our secondary aim was to identify subgroups of survivors who might have specific needs in terms of follow-up or after-care services.

\section{Methods}

\section{Data source}

We derived data from the National Cancer Registry (NCR). Since 1994, the NCR has aimed to identify all incident cancers in the population usually resident in Ireland. An active registration process is implemented by trained tumour registration officers (TROs) each of whom has responsibility for recording data on newly diagnosed cancers from a defined group of hospitals. Cases are identified through histopathology reports, the hospital inpatient system, and records from radiotherapy units, oncology wards, day units and pharmacies. Follow-up is achieved by regular linkage with death certificates, provided by the Central Statistics Office, supplemented with information from medical records for a small proportion of cases. Death certificates are matched, using personal identifying details, to cancer registrations using probabilistic linkage methods, supplemented by manual checking. The Registry records date and cause of death for the matched cases. Completeness of registration is estimated to be at least $97 \%$ [28].

\section{Estimating prevalence}

We abstracted details of people with all primary invasive cancers (International Classification of Diseases $10^{\text {th }}$ revision (ICD10): C00-C96) diagnosed during 1994-2011, who were still alive on 31/12/2011, thus providing an estimate of 17-year prevalence. We excluded small numbers of cases for which sex $(n=13)$ or date of birth $(n=340)$ was unknown. Our initial estimates for all cancers include non-melanoma skin cancers (NMSC; C44) but, since most registries do not record complete data on NMSC, these were excluded from subsequent analyses in order to permit international comparisons. Prevalence is based on individuals rather than tumours so only the first diagnosed 
tumour for a site was counted. Therefore, in analyses of all cancers combined, people who were diagnosed with multiple primary cancers were counted once, according to the date of diagnosis of their first cancer. The same was done for sites where an individual may have been diagnosed with more than one tumour (e.g. breast). For other sites, an individual with multiple primary cancers contributed to the prevalence for each site (e.g. prostate and lung).

\section{Statistical analysis}

Information on cancer-directed treatments received within a year of diagnosis was used to classify survivors according to whether or not they had received (i) cancer-directed surgery, (ii) chemotherapy, (iii) radiotherapy or (iv) hormone therapy as part of their initial management. Analysis involved categorizing prevalent cancers by cancer site, sex, marital status at diagnosis (married, single, divorced/separated/widowed, unknown), age group at 31/12/2011 $(<40$, $40-49,50-59,60-69,70-79, \geq 80)$ and time since diagnosis ( $<1$ year, $1-4.99$ years, $5-9.99$ years, $\geq 10$ years). Associations between the socio-demographic and clinical variables were investigated using chi-square tests.

\section{Results}

In total, 178,813 people in Ireland were diagnosed with an invasive cancer during 1994-2011 and were still alive on $31 / 12 / 2011$. 90,835 (51\%) of these survivors were female and 87,978 (49\%) were male. When NMSC was excluded, there were 112,610 cancer survivors at $31 / 12$ / 2011 , of whom 58,054 (52\%) were female and 54,556 (48\%) were male.

\section{Cancer site}

The most prevalent cancer in both sexes was NMSC: 66,203 people (32,781 females; 33,422 males) were diagnosed with NMSC and no other invasive cancers during 1994-2011 and were still alive at 31/12/2011. Table 1 shows the ten most prevalent cancers in females and males after excluding NMSC. In females, breast cancer (26,066 survivors) dominated with more than four-times as many survivors as the next most prevalent cancer, colorectum $(6,598)$. The third most prevalent cancer was melanoma of the skin $(4,593)$, followed by cancer of the uterus $(3,505)$. Other female gynaecological cancers also featured among the most prevalent sites (cervix, 2,617; ovary, 1,833$)$. In males, prostate cancer was most prevalent $(23,966)$ followed by colorectum $(8,207)$, lymphoma $(3,236)$ and melanoma $(2,774)$.

When the 15 most common cancers which affect both sexes (other than NMSC) were considered, the proportion of survivors who were female was lowest for bladder and head \& neck cancer (both 29\%; Figure 1). It was around $40 \%$ for cancers of the oesophagus, stomach and kidney and for leukaemia, and almost $50 \%$ for cancers of the brain \& CNS, lung and unknown primary, and lymphomas. The only sites for which female survivors exceeded males were melanoma (62\% female), thyroid (77\% female) and breast (99\% female).

\section{Age and marital status}

The age distribution of survivors of all invasive cancers (excluding NMSC) differed significantly by sex (Table 2; $\left.\mathrm{chi}^{2} \mathrm{p}<0.001\right)$. Female survivors were younger on average: $39 \%$ were aged under 60 at the end of 2011 compared to $25 \%$ of males. In contrast, $35 \%$ of females were aged 70 or older, compared to $46 \%$ of males. The age-distribution of survivors varied by cancer site (Figures 2(a) and (b)). For breast cancer in females, $40 \%$ of survivors were under 60 , 30\% were aged $60-69,19 \%$ were aged $70-79$ and $12 \%$ were 80 or older. For prostate cancer, $11 \%$ were under 60 , $33 \%$ were $60-69,38 \%$ were $70-79$ and $18 \%$ were aged 80 or older. Other cancers for which approximately half, or more, of survivors were aged 70 or older were: bladder (males, 63\%), colorectum (females, 58\%; males, 57\%) and lung (females, 48\%; males, 49\%). The cancers for which

Table 1 Numbers of people diagnosed with cancer 1994-2011 and still alive at 31/12/2011, by sex and cancer site

\begin{tabular}{|c|c|c|c|c|}
\hline \multirow[b]{2}{*}{ Rank } & \multicolumn{2}{|l|}{ Females } & \multicolumn{2}{|l|}{ Males } \\
\hline & Site (ICD10) & No. of people & Site (ICD10) & No. of people \\
\hline 1 & Breast (C50) & 26,066 & Prostate (C61) & 23,966 \\
\hline 2 & Colorectal (C18-C21) & 6,598 & Colorectal (C18-C21) & 8,207 \\
\hline 3 & Melanoma (C43) & 4,593 & Lymphoma (C81-C85) & 3,236 \\
\hline 4 & Uterus (C54-C55) & 3,505 & Melanoma (C43) & 2,774 \\
\hline 5 & Lymphoma (C81-C85) & 2,914 & Bladder (C67) & 2,511 \\
\hline 6 & Cervix (C53) & 2,617 & Head \& neck (COO-C14, C30-C32) & 2,362 \\
\hline 7 & Ovary (C56) & 1,833 & Testis (C62) & 2,257 \\
\hline 8 & Lung (C33-C34) & 1,740 & Leukaemia (C91-C95) & 1,994 \\
\hline 9 & Leukaemia (C91-C95) & 1,386 & Lung (C33-C34) & 1,949 \\
\hline 10 & Kidney (C64-C66) & 1,262 & Kidney (C64-C66) & 1,916 \\
\hline
\end{tabular}




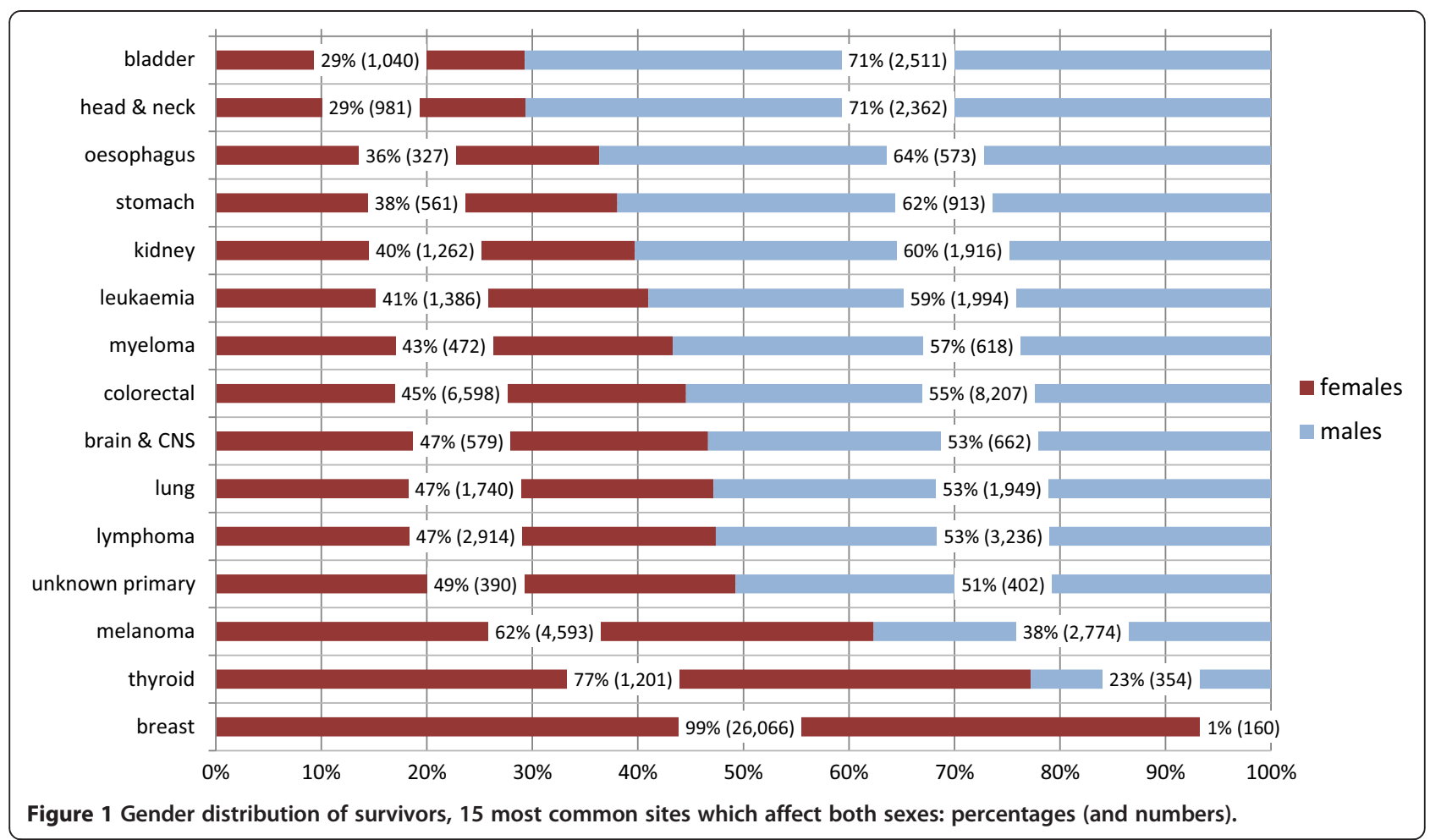

there were higher percentages of survivors aged under 40 were: lymphoma (females, 19\%; males, $20 \%$ ), cervix (20\%), leukaemia (females, 28\%; males, $22 \%$ ), and testis (50\%).

Considering all cancers (excluding NMSC), $61 \%$ of survivors were married at the time of diagnosis, $18 \%$ were single, $14 \%$ were divorced/widowed/separated, and for $7 \%$ their marital status was unknown. The marital status distribution varied significantly by sex $(\mathrm{p}<0.001)$ : the percentage who were married was lower among females than males ( $58 \%$ vs $65 \%)$ the percentage who were single was similar (females 17\%; males: 18\%); and the percentage who were divorced/widowed/separated was twice as high in females (19\% vs 9\%).

Table 2 Numbers of people diagnosed with cancer 1994-2011 and still alive at 31/12/2011, by sex and age $^{1}$, all invasive cancers ${ }^{2}$

\begin{tabular}{lccccc}
\hline & \multicolumn{2}{c}{ Females } & & \multicolumn{2}{c}{ Males } \\
\cline { 2 - 3 } \cline { 5 - 6 } Age-group & No. of people & $\%$ & & No. of people & $\%$ \\
\hline$<40$ & 4,218 & $7 \%$ & & 3,644 & $7 \%$ \\
$40-49$ & 6,347 & $11 \%$ & & 3,097 & $6 \%$ \\
$50-59$ & 12,115 & $21 \%$ & & 6,984 & $13 \%$ \\
$60-69$ & 15,030 & $26 \%$ & & 15,513 & $28 \%$ \\
$70-79$ & 11,830 & $20 \%$ & & 16,479 & $30 \%$ \\
$80+$ & 8,514 & $15 \%$ & & 8,839 & $16 \%$ \\
Total & 58,054 & $100 \%$ & & 54,556 & $100 \%$ \\
\hline
\end{tabular}

${ }^{2}$ age at 31/12/2011; ${ }^{2}$ excluding non-melanoma skin cancer.

\section{Time since diagnosis}

For all cancers combined (excluding NMSC), the distribution of time since diagnosis also differed significantly by sex (Table $3 ; p<0.001$ ). One quarter of female survivors had lived for 10 years or more with their cancer compared to only $18 \%$ of males. For both sexes, for all cancer sites with the exception of lung and testis, 10-15\% of survivors had been diagnosed less than one year previously; for lung cancer this figure was $30 \%$ in females and $33 \%$ in males; for testis cancer, it was 7\% (Figure 3(a) and (b)). The percentage of survivors who were at least one year, and less than five years, from diagnosis ranged from $31 \%$ (testis) to $43 \%$ (prostate). The percentage of longterm survivors ( $\geq 10$ years) varied between $21 \%$ and $28 \%$ for all sites in females with the exception of lung (12\%). For males, there was more site-specific variation in this percentage: it ranged from $12 \%$ and $13 \%$ for prostate and lung cancer respectively, to $30 \%$ and 31\% for bladder and testis cancer, respectively.

\section{Treatments received}

Overall, $69 \%$ of survivors had undergone cancer-directed surgery as part of their initial management, 39\% had received radiotherapy, 32\% had received chemotherapy and $18 \%$ had received hormone therapy (Table 4). These percentages were consistently higher for female than male survivors (surgery, $82 \%$ vs $54 \%$; radiotherapy, $42 \%$ vs $35 \%$; chemotherapy, $40 \%$ vs $22 \%$; and hormone therapy, $23 \%$ vs $13 \%)$. The percentage who had undergone 
(a)

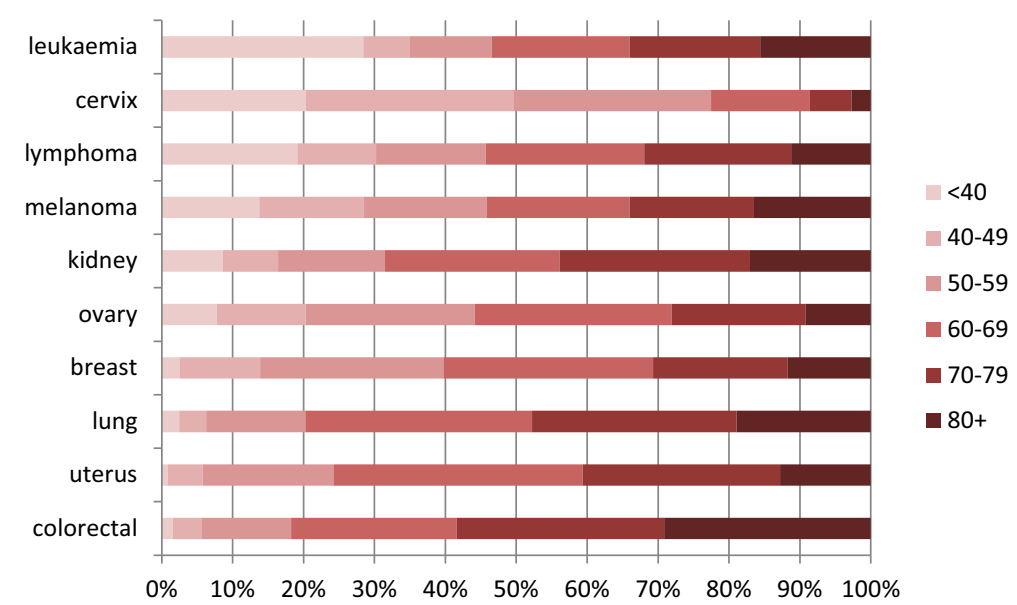

(b)

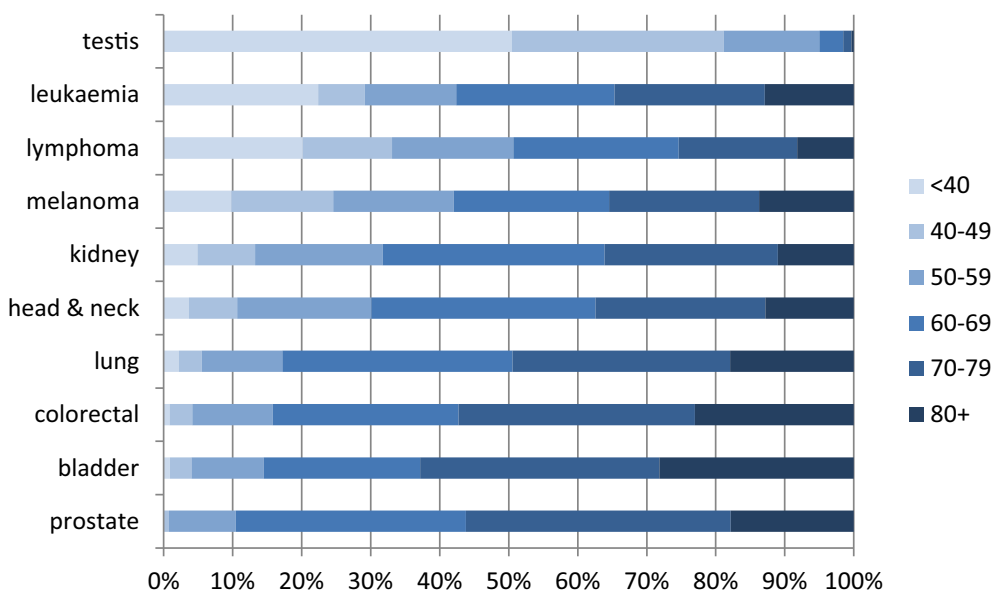

Figure 2 Percentages of people diagnosed with cancer 1994-2011 and still alive at 31/12/2011, by age at 31/12/2011 and sex, ten most prevalent cancers in females and males (a) Females (b) Males.

radiotherapy was lowest in the youngest and oldest survivors; chemotherapy receipt decreased with increasing age; and hormone therapy receipt was highest in the oldest age-group. Among the commonest cancers, radiotherapy was most frequent among survivors of prostate (46\%),

Table 3 Numbers of people diagnosed with cancer 1994-2011 and still alive at 31/12/2011, by sex and time since diagnosis ${ }^{1}$, all invasive cancers ${ }^{2}$

\begin{tabular}{lccccc}
\hline & \multicolumn{2}{c}{ Females } & & \multicolumn{2}{c}{ Males } \\
\cline { 2 - 3 } \cline { 5 - 6 } Time since diagnosis & No. of people & $\%$ & & No. of people & $\%$ \\
\hline$<1$ year & 6,915 & $12 \%$ & 7,809 & $14 \%$ \\
$1-4.99$ years & 20,321 & $35 \%$ & 21,156 & $39 \%$ \\
$5-9.99$ years & 16,224 & $28 \%$ & & 15,586 & $29 \%$ \\
$10+$ years & 14,594 & $25 \%$ & & 10,005 & $18 \%$ \\
Total & 58,054 & $100 \%$ & 54,556 & $100 \%$
\end{tabular}

at 31/12/2011; ${ }^{2}$ excluding non-melanoma skin cancer. head \& neck (65\%) and breast (66\%) cancer. More than half of survivors with breast cancer (51\%), leukaemia (56\%), ovarian cancer (64\%) and lymphoma (74\%) had received chemotherapy. Half of breast cancer survivors and $28 \%$ of prostate cancer survivors had received hormone therapy.

\section{Discussion}

Prevalence is increasingly considered an important measure of the population-level cancer burden. Although some recent studies have estimated prevalence (see [29] and references therein), few (if any) set out explicitly to examine socio-demographic and clinical heterogeneity within the survivor population in order to inform the development of strategies for service provision around cancer follow-up and supportive care.

We estimated that, in total, 178,813 people had been diagnosed with an invasive primary cancer in Ireland 
(a)

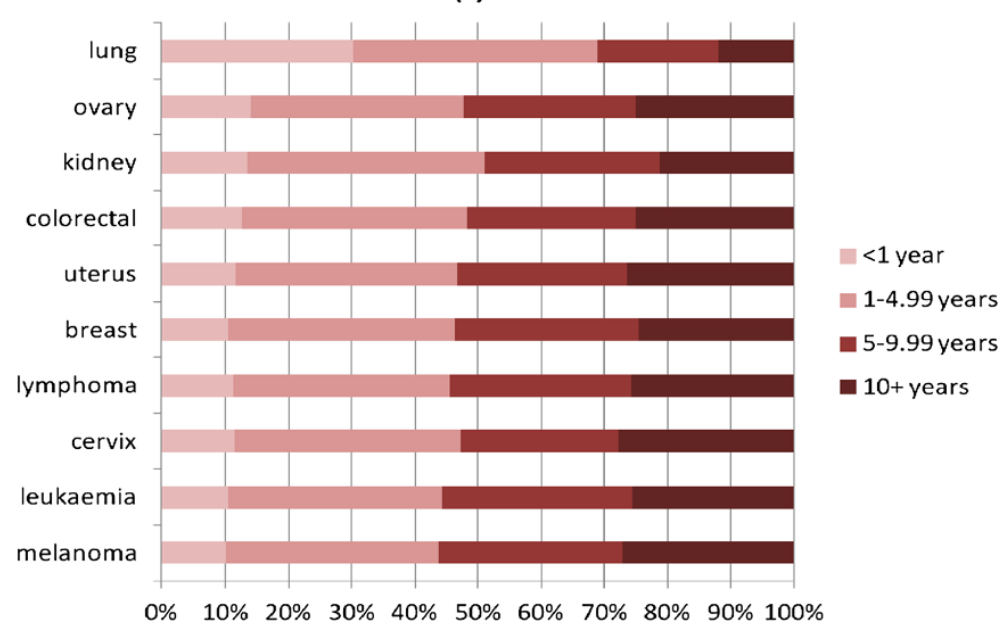

(b)

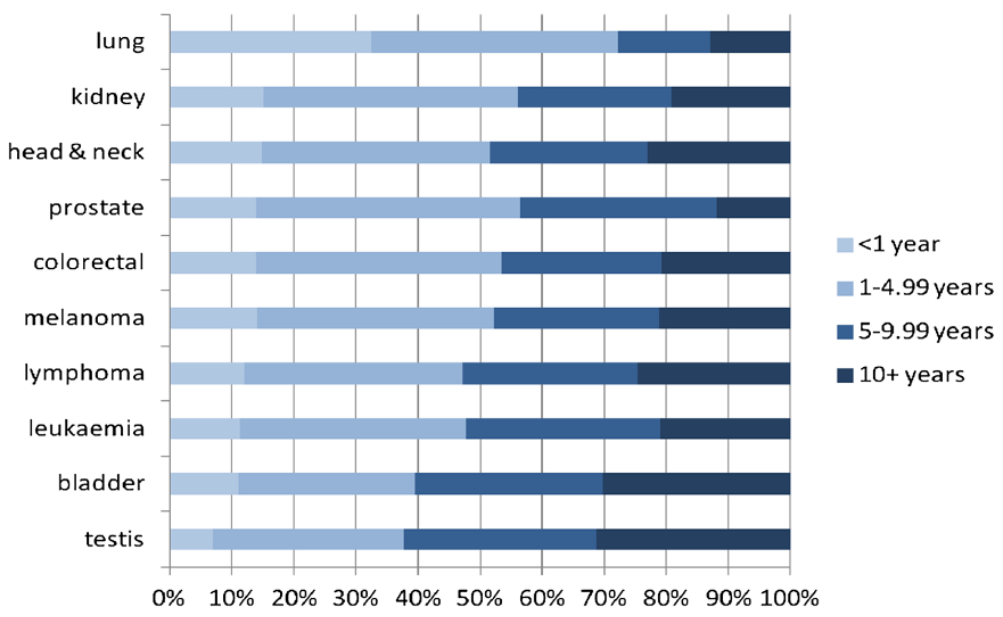

Figure 3 Percentages of people diagnosed with cancer 1994-2011 and still alive at 31/12/2011, by time since diagnosis and sex, ten most prevalent cancers in females and males (a) Females (b) Males.

during 1994-2011 and were alive at the end of 2011. Expressed crudely in relation to the 2011 population, this means that at least $3.9 \%$ of the population of Ireland are cancer survivors. In addition, it implies that each general practitioner has, on average, 60 patients who are cancer survivors. The NCR is unusual in that it aims to record all NMSC cases. Since most other registries do not, in order to permit international comparisons, we repeated our analysis excluding NMSC. When this was done, there were 112,610 survivors, representing $2.4 \%$ of the male, and $2.5 \%$ of the female, population. These figures are very close to the estimate of 18-year prevalence at the end of 2010 in Northern Ireland (2.5\%) [30]. In contrast they are somewhat lower than estimates for Switzerland, Italy and the United Kingdom (UK) [31-33], but these studies estimated complete prevalence (i.e. all survivors) whereas we considered limited duration (i.e. 17-year) prevalence because national cancer registration was not established until 1994. Therefore, the figures in this paper provide a lower bound for the total survivor population in Ireland, and thus the number of people who may require some level of access to cancer follow-up and/or after-care services.

Because prevalence is a function of incidence and survival, there are some notable differences between the cancers which rank highest when incidence or mortality are considered and those which are most prevalent. For example, testicular cancer, which is relatively uncommon but has good survival (175 new cases and 5 deaths per annum in Ireland [4]), is the $14^{\text {th }}$ most commonly-diagnosed cancer among men but ranked $7^{\text {th }}$ in terms of prevalence. In contrast, lung cancer - the $3^{\text {rd }}$ most commonly diagnosed cancer and most common cause of cancer death in both sexes [4] - ranked $8^{\text {th }}$ (females) and $9^{\text {th }}$ (males) when prevalence was considered. Similar patterns are evident in Northern Ireland [30] and the United 
Table 4 Number and percentage of people diagnosed with cancer 1994-2011 and still alive at 31/12/2011, who had had cancer-directed surgery, chemotherapy, radiotherapy or homone therapy, overall and by age and time since diagnosis $^{1}$, all invasive cancers ${ }^{2}$

\begin{tabular}{|c|c|c|c|c|c|c|c|c|}
\hline & \multicolumn{2}{|c|}{ Cancer-directed surgery } & \multicolumn{2}{|c|}{ Chemotherapy } & \multicolumn{2}{|c|}{ Radiotherapy } & \multicolumn{2}{|c|}{ Homone therapy } \\
\hline & No. & $\%$ & No. & $\%$ & No. & $\%$ & No. & $\%$ \\
\hline \multicolumn{9}{|l|}{ Age-group } \\
\hline$<40$ & 5,113 & $65 \%$ & 3,915 & $50 \%$ & 2,147 & $27 \%$ & 302 & $4 \%$ \\
\hline $40-49$ & 7,630 & $81 \%$ & 4,330 & $46 \%$ & 3,760 & $40 \%$ & 1,369 & $14 \%$ \\
\hline $50-59$ & 14,855 & $78 \%$ & 8,278 & $43 \%$ & 8,471 & $44 \%$ & 3,693 & $19 \%$ \\
\hline $60-69$ & 21,226 & $69 \%$ & 9,950 & $33 \%$ & 13,284 & $43 \%$ & 5,603 & $18 \%$ \\
\hline $70-79$ & 17,801 & $63 \%$ & 6,921 & $24 \%$ & 11,658 & $41 \%$ & 5,669 & $20 \%$ \\
\hline $80+$ & 10,831 & $62 \%$ & 2,315 & $13 \%$ & 4,070 & $23 \%$ & 3,706 & $21 \%$ \\
\hline \multicolumn{9}{|c|}{ Time since diagnosis } \\
\hline$<1$ year & 7,422 & $50 \%$ & 3,350 & $23 \%$ & 2,970 & $20 \%$ & 1,470 & $10 \%$ \\
\hline $1-4.99$ years & 27,804 & $67 \%$ & 13,831 & $33 \%$ & 17,746 & $43 \%$ & 8,457 & $20 \%$ \\
\hline $5-9.99$ years & 22,796 & $72 \%$ & 10,553 & $33 \%$ & 13,789 & $43 \%$ & 6,283 & $20 \%$ \\
\hline $10+$ years & 19,434 & $79 \%$ & 7,975 & $32 \%$ & 8,885 & $36 \%$ & 4,132 & $17 \%$ \\
\hline Total & 77,456 & $69 \%$ & 35,709 & $32 \%$ & 43,390 & $39 \%$ & 20,342 & $18 \%$ \\
\hline
\end{tabular}

${ }^{1}$ at 31/12/2011; ${ }^{2}$ excluding non-melanoma skin cancer.

States [34]. The implication of these observations for service providers is that the cancer-specific composition (or configuration) of services for diagnosis and treatment should be different from that for rehabilitation, follow-up and after-care services (because the composition of the types of cancers requiring diagnosis/ treatment and follow-up/after-care differs).

The rationale for examining prevalence by time since diagnosis is that survivors at different "phases" of follow-up/survivorship may have different needs. For example, many of those who have survived the first year post-diagnosis may be in need of (or benefit from) rehabilitation services [35]; the higher prevalence of anxiety in those who have survived two or more years post-diagnosis than among controls [36], suggests psychological support services could be of benefit to notable proportions of intermediate-term survivors; while long-term survivors (i.e. survived $\geq 10$ years) may be in need of services focused on the detection and management of late-effects of treatment and/or second primaries. The distribution of time since diagnosis for all invasive cancers in this analysis was almost identical to that seen in Northern Ireland [30]. The observed higher percentage of longer-term survivors among females is driven in large-part by breast cancer: almost 6,500 women had survived for $\geq 10$ years after a breast cancer diagnosis. Moreover, two-thirds of breast cancer survivors had received radiotherapy and half had received chemotherapy. Radiotherapy to the breast and trastuzamab are associated with risk of late cardiac complications $[11,12]$ and those responsible for follow-up care for longterm breast cancer survivors need to be alert to these risks.
We found that $15 \%$ of survivors were younger than 50 and a further $17 \%$ were aged 50-59. The concerns, and hence burden of supportive care needs, of younger and older survivors may be quite different [23]. For example, younger survivors may be more concerned about employment and related financial matters, relationships, and fertility and sexuality issues [37-39]. In addition, they may adapt less well to having cancer than older survivors [40]. Our findings with regard to the age distribution of different cancers suggest that follow-up and after-care services and supports for survivors of leukaemia, lymphoma and melanoma and testicular and cervical cancer should encompass these types of issues.

At the other end of the age spectrum, four in every 10 survivors were aged 70 or older. This means that at least $12.6 \%$ of this age-group in Ireland (16.1\% of males; $9.9 \%$ of females) has a history of invasive cancer other than NMSC. Older survivors tend to have more comorbidities than younger survivors [40]. They also have high levels of psychological distress related to the continuing effects of cancer and its treatment, significant limitations in physical functioning, and higher rates of frailty than the general population [41-43]. These issues are inter-related and may be exacerbated by lifestyle factors $[42,44]$. Our results therefore suggest that follow-up and after-care services for survivors of bladder, colorectal and lung cancer, in particular, should be linked closely to geriatric and other non-cancer specialties, and should be broad ranging. It is noteworthy, however, that while there have been trials of alternative models of follow-up for some of these cancers [45,46], models specifically focused on older survivors needs, or which explicitly seek to involve 
geriatric and other-specialties, do not appear to have been evaluated.

In some studies unmarried survivors have higher supportive care needs [23]. Thirty-two percent of our survivor population was not married at the time of diagnosis, and this figure was higher among older survivors $(\geq 70,35 \%$; $\geq 80,47 \%$ ), providing further evidence to suggest that the elderly survivor population may have pronounced needs. In Ireland, among the elderly, living alone is a marker of poverty and experiencing multiple types of enforced deprivation [47]. Since socio-economic status influences access to cancer care [48-51], in developing supportive care services it will be important to consider strategies and approaches for minimizing inequalities in access.

The higher proportion of female to male survivors in this study echoes findings elsewhere $[30,34]$ and is a function of the dominance of breast cancer among women. As in the United States and UK [33,34], more than $40 \%$ of female survivors in Ireland had a history of breast cancer. Among breast cancer survivors unmet needs are common, are present across the survivorship continuum, and often relate to emotional or existential concerns (see, for example, [52,53]), suggesting that after-care services for both shorter-term and longer-term breast cancer survivors should encompass these types of issues.

Just under half of survivors in Ireland were male (48\%), higher than figures from Northern Ireland (43\%) and the UK as a whole $(41 \%)[30,33]$. This is due to prostate cancer incidence in Ireland, which was estimated to be the highest in Europe in 2008 [54]. This high incidence is a consequence of widespread prostate specific antigen testing in primary care [55]. Indeed, $42 \%$ of the male survivors in Ireland had been diagnosed with prostate cancer, almost identical to the US (43\%) [34]. Prostate cancer treatments are associated with significant side-effects which can impact adversely on health-related quality-oflife [56]. Prevalence of related side-effects is high, even years after treatment [57] and, although there are interventions available for the management of these, men often do not receive information about what is available (M Hennessy, personal communication). This suggests that there may be significant needs for physical, psychological and psychosexual support among prostate cancer survivors.

This study was based on high-quality cancer registration data. Although registration completeness is high [28], a small proportion of cases is missed by the Registry, meaning that these figures slightly under-estimate true 17-year prevalence; the extent of this under-estimation is likely to vary by site. Accurate prevalence estimates also require comprehensive death registration and the ability to perform accurate linkage between death certificates and cancer registrations. While death ascertainment is likely to be high in Ireland, it is possible that some people diagnosed with cancer left Ireland and subsequently died before the end of 2011; these deaths would not be known to the Registry. As noted earlier, these figures do not claim to be estimates of the total number of survivors in particular, they underestimate the true number of longterm survivors (i.e. they do not include people diagnosed with cancer before 1994 and who were still alive at the end of 2011). While methods are available for estimating total prevalence $[58,59]$, these require assumptions which may not be valid. Moreover, it might be argued that many of those who have survived cancer for at least 18 years are likely to be at low risk of recurrence and have little need for active follow-up. Therefore, it has been suggested that limited duration prevalence is likely to be more pertinent for estimating the needs for cancer services according to specific phases of cancer care [29]. In terms of other limitations, these analyses do not identify those survivors whose cancer was cured, those in active therapy or those dying from cancer; this information is not available through the Registry. Nor do they reveal anything directly about the health status, or unmet supportive care needs, of survivors. Evidence is accruing that aspects of health-related quality-of-life may vary by survivors' socio-economic, urban/rural, or immigrant status [60-64] suggesting that supportive care needs may also vary and, in turn, that estimates of the prevalence of survivors in different socio-economic groups, for example, could be valuable for service planning. We did not consider these characteristics and this is a limitation of the study. Finally, these figures are a snap-shot of prevalence at one point in time. As in other developed countries, cancer incidence in Ireland will continue to rise in coming years [65]; even if survival does not improve, the numbers of cancer survivors will grow, particularly in the older age groups. Estimates of this future burden are also needed to help providers make provision for this booming population.

\section{Conclusion}

In conclusion, this study shows that data from cancer registries can provide a population-based estimate of the number of cancer survivors, information likely to be of considerable value to service planners and providers in the statutory and voluntary sectors. They also reveal important heterogeneity within the survivor population - which is likely to determine (at least in part) their ongoing medical and supportive care needs and hence influence service requirements - and provide an indication of the likely magnitude of groups of survivors who may have specific service and support needs (e.g. testicular cancer survivors, survivors of leukaemia and lymphoma, long-term breast cancer survivors, unmarried survivors, elderly survivors). Figures such as these provide an important first step in informing development of follow-up and 
after-care services, supports and other initiatives which will effectively meet survivors' needs.

\section{Abbreviations}

ICD10: International Classification of Diseases $10^{\text {th }}$ revision; NCR: National Cancer Registry; NMSC: Non-melanoma skin cancer; TRO: Tumour registration officer; UK: United Kingdom.

\section{Competing interests}

The authors declare that they have no competing interests.

\section{Authors' contributions}

LS conceived of the study, directed the analysis and drafted the manuscript; SD undertook the analysis, contributed to interpretation and commented on the manuscript; $\mathrm{HC}$ oversaw data collection, contributed to interpretation and commented on the manuscript; other authors (PG, MM, AP, AAT, AT) contributed to interpretation and commented on the manuscript. All authors read and approved the final manuscript.

\section{Acknowledgements}

We are grateful to the NCR tumour registration officers and data processing staff who collected the data which formed the basis of this paper.

\section{Funding}

This study was conducted under the auspices of an Interdisciplinary Capacity Enhancement award from the Health Research Board (ICE/2012/9) which supports AP, AAT and AT. The National Cancer Registry (NCR) is funded by the Department of Health.

\section{Author details}

${ }^{1}$ National Cancer Registry, Building 6800, Cork Airport Business Park, Kinsale Road, Cork, Ireland. ${ }^{2}$ Dublin City University, Dublin, Ireland. ${ }^{3}$ National University of Ireland, Galway, Ireland.

Received: 27 January 2014 Accepted: 24 September 2014 Published: 15 October 2014

\section{References}

1. Ferlay J, Autier P, Boniol M, Heanue M, Colombet M, Boyle P: Estimates of the cancer incidence and mortality in Europe in 2006. Ann Oncol 2007, 18:581-592.

2. Ferlay J, Steliarova-Foucher E, Lortet-Tieulent J, Rosso S, Coebergh JW, Comber H, Forman D, Bray F: Cancer incidence and mortality patterns in Europe: estimates for 40 countries in 2012. Eur J Cancer 2013, 49:1374-1403.

3. Verdecchia A, Guzzinati S, Francisci S, De Angelis R, Bray F, Allemani C, Tavilla A, Santaquilani M, Sant M, EUROCARE Working Group: Survival trends in European cancer patients diagnosed from 1988 to 1999. Eur J Cancer 2009, 45:1042-1066.

4. National Cancer Registry: Cancer in Ireland 2013. Annual Report of the National Cancer Registry. Cork: National Cancer Registry; 2013.

5. Macmillan Cancer Support: Two million reasons. The cancer survivorship agenda. London: Macmillan Cancer Support; 2008.

6. Hewitt M, Greenfield S, Stovall E (Eds): From cancer patient to cancer survivor. Lost in transition. Washington DC: The National Academies Press; 2005.

7. Galbraith ME, Hays $L$, Tanner T: What men say about surviving prostate cancer: complexities represented in a decade of comments. Clin J Oncol Nurs 2012, 16:65-72.

8. Sandsund C, Pattison N, Doyle N, Shaw C: Finding a new normal: a grounded theory study of rehabilitation after treatment for upper gastrointestinal or gynaecological cancers-the patient's perspective. Eur J Cancer Care (Engl) 2013, 22:232-244.

9. Sherman DW, Rosedale M, Haber J: Reclaiming life on one's own terms: a grounded theory study of the process of breast cancer survivorship. Oncol Nurs Forum 2012, 39:E258-E268.

10. Janssen-Heijnen ML, Houterman S, Lemmens VE, Louwman MW, Maas HA, Coebergh JW: Prognostic impact of increasing age and co-morbidity in cancer patients: a population-based approach. Crit Rev Oncol Hematol 2005, 55:231-240.
11. Kalam K, Marwick TH: Role of cardioprotective therapy for prevention of cardiotoxicity with chemotherapy: a systematic review and metaanalysis. Eur J Cancer 2013, 49:2900-2909.

12. Raj KA, Marks LB, Prosnitz RG: Late effects of breast radiotherapy in young women. Breast Dis 2005, 23:53-65.

13. Miller MP, Stanley TV: Results of a mass screening program for colorectal cancer. Arch Surg 1988, 123:63-65.

14. Keating NL, O'Malley A, Freedland SJ, Smith MR: Diabetes and cardiovascular disease during androgen deprivation therapy: observational study of veterans with prostate cancer. J Natl Cancer Inst 2012, 104:1518-1523.

15. Sioka C, Kyritsis AP: Central and peripheral nervous system toxicity of common chemotherapeutic agents. Cancer Chemother Pharmacol 2009, 63:761-767.

16. Valdivieso M, Kujawa AM, Jones T, Baker LH: Cancer survivors in the United States: a review of the literature and a call to action. Int J Med Sci 2012, 9:163-173.

17. Corner J: Addressing the needs of cancer survivors: issues and challenges. Expert Rev Pharmacoecon Outcomes Res 2008, 8:443-451.

18. Newell S, Sanson-Fisher RW, Girgis A, Ackland S: The physical and psychosocial experiences of patients attending an outpatient medical oncology department: a cross-sectional study. Eur J Cancer Care 1999, 8:73-82.

19. Smith DP, Supramaniam R, King MT, Ward J, Berry M, Armstrong BK: Age, health, and education determine supportive care needs of men younger than 70 years with prostate cancer. J Clin Oncol 2007, 25:2560-2566.

20. Ream E, Quennell A, Fincham L, Faithfull S, Khoo V, Wilson-Barnett J, Richardson A: Supportive care needs of men living with prostate cancer in England: s survey. Br J Cancer 2008, 98:1903-1909.

21. Harrison JD, Young JM, Price MA, Butow PN, Solomon MJ: What are the unmet supportive care needs of people with cancer? A systematic review. Support Care Cancer 2009, 17:1117-1128.

22. Krouse RS, Herrinton $\sqcup$, Grant M, Wendel CS, Green SB, Mohler MJ, Baldwin CM, McMullen CK, Rawl SM, Matayoshi E, Coons SJ, Hornbrook MC: Health-related quality of life among long-term rectal cancer survivors with an ostomy: manifestations by sex. J Clin Oncol 2009, 27:4664-4670.

23. Puts MT, Papoutsis A, Springall E, Tourangeau AE: A systematic review of unmet needs of newly diagnosed older cancer patients undergoing active cancer treatment. Support Care Cancer 2012, 20:1377-1394.

24. Giles G: How important are estimates of cancer prevalence? Ann Oncol 2002, 13:815-816.

25. Bastos J, Peleteiro B, Gouveia J, Coleman MP, Lunet N: The state of the art of cancer control in 30 European countries in 2008. Int J Cancer 2010, 126:2700-2715.

26. Parkin DM: The evolution of the population-based cancer registry. Nat Rev Cancer 2006, 6:603-612.

27. Brewster DH, Coebergh JW, Storm HH: Population-based cancer registries: the invisible key to cancer control. Lancet Oncol 2005, 6:193-195.

28. O'Brien K, Comber H, Sharp L: Completeness of case ascertainment at the Irish National Cancer Registry. Ir J Med Sci 2014, 183:219-24.

29. Bray F, Ren JS, Masuyer E, Ferlay J: Global estimates of cancer prevalence for 27 sites in the adult population in 2008. Int J Cancer 2013, 132 (5):1133-1145.

30. N. Ireland Cancer Registry, Queens University Belfast, HSC Public Health Agency, Macmillan Cancer Support: Living with and beyond cancer. A report on cancer prevalence in Northern Ireland 2010. Belfast: N. Ireland Cancer Registry; 2013

31. Herrmann C, Cerny T, Savidan A, Vounatsou P, Konzelmann I, Bouchardy C, Frick H, Ess S: Cancer survivors in Switzerland: a rapidly growing population to care for. BMC Cancer 2013, 13:287-2407. 3-287.

32. De Angelis R, Grande E, Inghelmann R, Francisci S, Micheli A, Baili P, Meneghini E, Capocaccia R, Verdecchia A: Cancer prevalence estimates in Italy from 1970 to 2010. Tumori 2007, 93:392-397.

33. Maddams J, Brewster D, Gavin A, Steward J, Elliott J, Utley M, Møller H: Cancer prevalence in the United Kingdom: estimates for 2008. Br J Cancer 2009, 101:541-547.

34. Siegel R, DeSantis C, Virgo K, Stein K, Mariotto A, Smith T, Cooper D, Gansler T, Lerro C, Fedewa S, Lin C, Leach C, Cannady RS, Cho H, Scoppa S, Hachey M, Kirch R, Jemal A, Ward E: Cancer treatment and survivorship statistics, 2012. CA Cancer J Clin 2012, 62:220-241

35. Maher J, McConnell H: New pathways of care for cancer survivors: adding the numbers. Br J Cancer 2011, 105:S5-S10. 
36. Mitchell AJ, Ferguson DA, Gill J, Paul J, Symonds P: Depression and anxiety in long-term survvors compared to spouses and healthy controls: a systematic review and meta-analysis. Lancet Oncol 2013, 14:721-732.

37. Li WW, Lam WW, Au AH, Ye M, Law WL, Poon J, Kwong A, Suen D, Tsang J, Girgis A, Fielding R: Interpreting differences in patterns of supportive care needs between patients with breast cancer and patients with colorectal cancer. Psychooncology 2013, 22:792-798.

38. Smith A, King M, Butow $P$, Luckett $T$, Grimison $P$, Toner GC, Stockler M Hovey E, Stubbs J, Hruby G, Gurney H, Turner S, Alam M, Cox K, Olver I: The prevalence and correlates of supportive care needs in testicular cancer survivors: a cross-sectional study. Psychooncology 2013, 22:2557-2564.

39. Timmons A, Gooberman-Hill R, Sharp L: "It's a time in your life when you are most vulnerable": a qualitative exploration of the financial impact of a cancer diagnosis and implications for financial protection in health. PLoS One 2013, 8:1-11.

40. Parry C, Kent EE, Mariotto AB, Alfano CM, Rowland JH: Cancer survivors: a booming population. Cancer Epidemiol Biomarkers Prev 2011, 20:1996-2005.

41. Deimling GT, Kahana B, Bowman KF, Schaefer ML: Cancer survivorship and psychological distress in later life. Psycho-oncol 2002, 11:479-494.

42. Bellury L, Pett MA, Ellington L, Beck SL, Clark JC, Stein KD: The effect of ageing and cancer on the symptom experience and physical function of elderly breast cancer survivors. Cancer 2012, 118:6171-6178.

43. Bennett JA, Winters-Stone KM, Dobek J, Nail JM: Frailty in older breast cancer survivors: age, prevalence, and associated factors. Oncol Nurs Forum 2013, 40:E126-E134.

44. Vrov EK, Fossa SD, Dahl AA: Is somatic comorbidity associated with more somatic symptoms, mental distress, or unhealthy lifestyle in elderly cancer survivors. J Cancer Surviv 2009, 3:109-116.

45. Moore S, Corner J, Haviland J, Wells M, Salmon E, Normand C, Brada M, O'Brien M, Smith I: Nurse led follow up and conventional medical follow up in management of patients with lung cancer: randomised trial. BMJ 2002, 325:1145-1151.

46. Wattchow DA, Weler DA, Esterman A, Pilotto LS, McGorm K, Hammett Z, Platell C, Silagy C: General practice vs surgical-based follow-up for patients with colon cancer: randomised controlled trial. Br J Cancer 2006, 94:1116-1121.

47. Central Statistics Office: Survey on Income and Living Conditions (SILC) Thematic Report on the Elderly, 2004, 2009 and 2010. Available at URL: http://www.cso.ie/en/media/csoie/releasespublications/documents/silc/ 2010/elderly/0409and10.pdf [Accessed 28th October 2014].

48. Raine R, Wong W, Scholes S, Ashton C, Obichere A, Ambler G: Social variations in access to hospital care for patients with colorectal, breast, and lung cancer between 1999 and 2006: retrospective analysis of hospital episode statistics. BMJ 2010, 340:b5479.

49. Forrest LF, Adams J, Wareham H, Rubin G, White M: Socioeconomic inequalities in lung cancer treatment: systematic review and meta-analysis. PLoS Med 2013, 10:e1001376.

50. Mohd Noor A, Sarker D, Vizor S, McLennan S, Hunter S, Suder A, Moller H, Spicer JF, Papa S: Effect of patient socioeconomic status on access to early-phase cancer trials. J Clin Oncol 2013, 31:224-230.

51. Paterson HM, Mander BJ, Muir P, Phillips HA, Wild SH: Deprivation and access to treatment for colorectal cancer in Southeast Scotland 2003-2009. Colorectal Dis 2014, 16:051-7.

52. Vivar CG, McQueen A: Informational and emotional needs of long-terms survivors of breast cancer. J Adv Nurs 2005, 51:520-528.

53. Hodgkinson K, Butow P, Hunt GE, Pendlebury S, Hobbs KM, Wain G: Breast cancer survivors' supportive care needs 2-10 years after diagnosis. Support Cancer Care 2007, 15:515-523.

54. Ferlay J:P,DM, Steliarova-Foucher E: Estimates of cancer incidence and mortality in Europe in 2008. Eur J Cancer 2010, 46:765-781.

55. Carsin AE, Drummond FJ, Black A, van Leeuwen PJ, Sharp L, Murray LJ, Connolly D, Egevad L, Boniol M, Autier P, Comber H, Gavin A: Impact of PSA testing and prostatic biopsy on cancer incidence and mortality: comparative study between the Republic of Ireland and Northern Ireland. Cancer Causes Control 2010, 21:1523-1531.

56. Gomella LG, Johannes J, Trabulsi EJ: Current prostate cancer treatments: effect on quality of life. Urology 2009, 73:S28-S35.

57. Kinnear H, Drummond F, Sharp L, Gavin A: An all-Ireland population-based study of past and current physical and psychological side-effects following prostate cancer. J Clin Urol 2013, 6:337-345.
58. Gail MH, Kessler L, Midthune D, Scoppa S: Two approaches for estimating disease prevalence from population-based registries of incidence and total mortality. Biometrics 1999, 55:1137-1144.

59. Mallone S, De Angelis R, van der Zwan JM, Trama A, Siesling S, Gatta G, Capocaccia R, The RARECARE WG: Methodological aspects of estimating rare cancer prevalence in Europe: The experience of the RARECARE project. Cancer Epidemiol 2013, 37:850-6.

60. Aarts MJ, Mols F, Thong MS, Louwman MW, Coebergh JW, van der PollFranse LV: Long-term prostate cancer survivors with low socio-economic status reported worse mental health-related quality of life in a population-based study. Urology 2010, 76:1224-1230.

61. Butow PN, Aldridge L, Bell ML, Sze M, Eisenbruch M, Jefford M, Schofiel $P$, Girgis A, King M, Duggal-Beri P, McGrane J, Goldstein D: Inferior healthrelated quality-of-life and psychological well-being in immigrant cancer survivors: a population-based study. Eur J Cancer 2013, 49:1948-1956.

62. Shin HW, Noh DY, Lee ES, Nam SJ, Park BW, Ahn SH, Yun YH: Correlates of existential well-being and their association with health-related quality of life in breast cancer survivors compared to the general population. Breast Cancer Res Treat 2009, 118:139-150.

63. Thomas AA, Timmons A, Molcho M, Pearce A, Gallagher P, Butow $P$, O'Sullivan E, Gooberman-Hill R, O'Neill C, Sharp L: Quality of Llfe in urban and rural settings: a study of head and neck cancer survivors. Oral Oncol 2014, 50:676-682.

64. Thomas AA, Gallagher P, O'Ceilleachair A, Pearce A, Sharp L, Molcho M: Distance from treating hospital and colorectal cancer survivors' quality of life: a gendered analysis. Support Care Cancer in press.

65. National Cancer Registry: Cancer projections for Ireland 2015-2040. Cork: National Cancer Registry; 2014.

\section{doi:10.1186/1471-2407-14-767}

Cite this article as: Sharp et al:: The magnitude and characteristics of the population of cancer survivors: using population-based estimates of cancer prevalence to inform service planning for survivorship care. BMC Cancer 2014 14:767.

\section{Submit your next manuscript to BioMed Central and take full advantage of:}

- Convenient online submission

- Thorough peer review

- No space constraints or color figure charges

- Immediate publication on acceptance

- Inclusion in PubMed, CAS, Scopus and Google Scholar

- Research which is freely available for redistribution 